مجلة كلية التربية الرياضية - جامعة بغداد ** المجلد الثلاثون ** العدد الثاني * لسنة

$r \cdot 1 \Lambda$

\title{
التغذية الراجعة النهائية المباشرة (الفورية) والمتأخرة وأثرها في تعلم حركات السباحة الحرة للطهلاب النبره المبتدئين
}

أ.م.د. سامر منصور جميل أ.د. مصطقى صلاح الدين

\section{مستخلص البحث باللغة العربية.}

أثنملت مشكلة البحث ان الباحثين لاحظا من خلا الدروس العملية لمادة السباحة وجود تباين كبير في درجات الطلاب في الشعب الدراسية المختلفة باختلاف التدريسي المسؤول عن الشعبة التي قد يكون سببه اختلاف الكيفية التي بعطي بهاء كل مدرس المعلومات التصحيحية (التغذية الراجعة)، فضلا عن تباين وقت اعطائها من تدريسي لاخر الامر الذي قد يكون سبيا لذلك التباين بين مستويات المتعلمين في نهاية الموسم الدراسي ، وبهذا فقد هدفت الدراسة الحالية الى معرفة اثر اسنخدام التغذية الراجعة المتأخرة والنهائية الفورية (المباشرة) في مستوى تعلم حركات السباحة الحرة لاى عينة البحث. ومعرفة اي النوعين من التخذية الراجعة المستخدمة (النهائية المباشرة والمتاخر) الاكثر تاثثر في تعلم حركات السباحة الحرة لاى عينة البحث وتمثلث عينة البحث اذ نم اختيارهم من مجتمع البحث من غير المتعلمين للسباحة ومن نفس المرحلة العمرية وباطوال واوزان متقاربة، وعلى اساس ذلك أستتتج الباحثان للتغذية الراجعة الفورية (المباشرة) والمتأخرة تأثيرا ايجابيا في تعلم حركات السباحة الحرة.فاعلية التغذية الراجعة الفورية في المجموعة الاولى لعينة البحث افضل من المجموعة الثانية في الاختبارات البعدية

\section{Abstract.}

\section{Immediate and Delayed Feedback and Their Effect on Learning Freestyle Swimming Movements for Beginner Students}

The problem of the research was that the researchers noticed through the practical lessons of swimming class that there is a great variation in the grades of the students in the different study subjects according to the teaching of the section which may be due to the difference in how each teacher gives the corrective information, From one teaching to the next, which may be the reason for this variance between the levels of learners at the end of the academic season Thus, the present study aimed at finding the effect of using immediate and delayed feedback on the level of learning freestyle swimming movements in 


\section{مجلة كلية التربية الرياضية - جامعة بغداد ** المجلد الثلاثون ** العدد الثاني * لسنة}

r. I 1

the subjects understudy. In addition to that, the research aimed at identifying the two types of feedback used (immediate and delayed) in learning freestyle swimming movements in the subjects. The researcher used the experimental method and the subjects were students of the physical education and sport Science College / University of Baghdad. The researchers concluded that immediate and delayed feedback has positive effects on learning freestyle swimming movements. Immediate feedback in the experimental group was better than the controlling group in the post-tests.

Keywords: immediate feedback, delayed feedback, freestyle swimming.

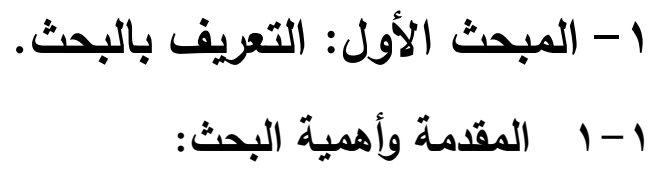

من المعروف ان نجاح اي عملية تعليمية تعتمد بشكل اساسي على ثلاث محاور اساسية لايختلف عليها اثثان وهي المعلم او المدرس المنهج التعليمي والمنلقي (المتعلم) ، وعليه فأن نجاح العملية التعليمية وتحقيق الهدف منها لاياتي الا بوجود منهج تعليمي صحيح مبني على الاسس العلمية بوجود المعلم اوالمدرس الذي بسنطيع تطبيق خطوات ذاللك المنهج بأسس صحيحة، أضافة الى وجود الطالب الذي يمنلك الرغبة والأرادة للتعلم.

وفي التعلم الحركي لاي فعالية او اي مهارة بتطلب وجود المحاور الثنلاث اعلاه التي هي المدرس و المنهج والطالب للنجاح في تعلم تللك المهارة او الفعالية المطلوبة.

اما في رياضة السباحة وبالرغم من انها من الرياضات المتعة التي تتصف بالطابع الترويحي،الا ان الحركات التي تتضمنها تعتبر من الحركات المركبة والصعبة التي تحتاج الى توافق عصبي عضلي عالي لتعلمها وادائها، ولكون هذه الحركات تؤدى في محيط جديد على المتعلم (الماء) لذا لايستطيع المتعلم رؤية حركاته خلال او اثثاء الاداء لذا بأني دور المعلم في تقديم واعطاء المعلومات اللازمة عن الاداء وبذلك ياتي الدور الرئيسي للتغذية الراجعة الخارجية في نجاح العملية التعليمية والوصول الى تحقيق اهدافها في القدرة على اداء السباحة واكتساب التعلم بالثكل الصحيح. وتحدث التغذية الراجعة نتيجة لطبيعة حركة الانسان فعندما يتحرك اي جزء من الجسم فأن معلومات خاصة بهذه الحركة آتية من عضلات ومفاصل ذلك الجزء تصل الى الدماغ لتوضح مدى وموضع ذلك الجزء وتمثل هذه استجابة داخلية طبيعية داخل الجسم، وفي الوقت نفسه هناك معلومات اخرى آتية عن طريق العين او ربما عن طريق الاذن اويحدث تداخل بين مصدرين اوأكثر تأتي منها المعلومات عن الحركة لتوضحها في الدماغ والتي تساعد المتعلم في معرفة ناتج ادائه لتلك الحركة، اذ أن معرفة نتائج الاداء الحركي من قبل المتعلمين بعد تتفيذهم لواجبات حركية معينة 
سواء اكانت مهارات أساسية أو رياضية تعد امرا مهما لتصحيح وتعزيز مسارات التعلم والاداء وأن هذا التصحيح يتم من خلال التعلم وخاصة بالنسبة للمبتدئين.

ويرى ( وجيه محجوب ) بان المعلومات التي يزود بها المتعلم عند ادائه الحركي من خلال تعلمه المهارة

تعد من أكثر المتغيرات اهمية في التعلم الحركي (10:؛ ())، وعلى هذا الاساس فان المعلومات حول الاستجابة او كفائة الاستجابة تبدو انها جوهرية خلال العملية التعليمية وان الاخفاق في تأمين منل هذه المعلومات في بعض الحالات سوف يمنع حدوث عملية التعلم كاملة كما ان اسلوب او طريقة تقديم هذه المعلومات هي ايضا مهمة للتعلم، وفي عملية تعلم السباحة بشكل خاص تكون لهذه المعلومات أهمية كبيرة في مساعدة المتعلم على اكتساب الحركات المطلوبة وتصحيح أخطاء ادائها عن طريق استخدام طرق وانواع التغذية الراجعة المناسبة وخصوصا ان هذه الحركات تؤدى في محيط جديد بالنسبة للمتعلم المبتديء لايستطيع فيه رؤية حركة اجزاء جسمه خلال الاداء، الامر الذي يجعل من الضروري على المدرس ان يعطي للمتعلم بأستمرار المعلومات الخاصة بأدائه الحركي، فمن خلاء مايعرض ويقدم للمبتديء من معلومات عن أهمية السباحة وفوائدها الصحية والاجتماعية يمكن ان يخلق له ذلك دافع او حافزا ايجابيا للتعلم والممارسة المستمرة

لهذه المهارة.

وهنا تكمن اهمية البحث في دراسة ناثير التخذية الراجعة الخارجية بنوعيها الفورية (المباشرة)والمنأخرة في تعلم حركات السباحة الحرة.

\section{r-1}

لقد اكدت الكثير من المصادر العلمية الأهمية الكبيرة للتغذية الراجعة في مختلف مجالات التعلم وخاصة التعلم الحركي اذ ان التغذية الراجعة واحدة من اهم الوسائل التي تسهل عملية التعلم، وبالرغم من اهمية تلك المعلومات التصحيحية، وعلى الرغم من وجود فريق من المدرسين الاكفاء وذوي الخبرة العالية في مجال تعليم السباحة في الكلية الا ان الباحثين لاحظا من خلال الدروس العملية لمادة السباحة وجود نباين كبير في درجات الطلاب في الثعب الدراسية المختلفة باختلاف التدريسي المسؤول عن الثعبة التي قد يكون سببه اختلاف الكيفية التي يعطي بهاء كل مدرس المعلومات التصحيحية (التغذية الراجعة )، فضلا عن تباين وقت اعطائها من تدريسي لاخر الامر الذي قد يكون سببا

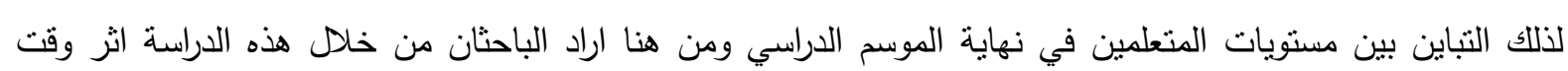
اعطاء التغذية الراجعة في مستوى تعلم الطلبة المتعلمين (المبتدئين) في السباحة. 
مجلة كلية التربية الرياضية - جامعة بغداد ** المجلد الثثلاثون ** العدد الثاني * لسنة

r. IN

r-l

ا. معرفة اثز اسنخدام التغذية الراجعة المتأخرة والنهائية الفورية (المباشرة) في مستوى تعلم حركات السباحة الحرة

لاى عينة البحث.

r. معرفة اي النوعين من التغذية الراجعة المستخدمة ( النهائية المباشرة والمتاخر) الاكثر ثاثير في تعلم حركات

السباحة الحرة لدى عينة البحث التجريبية.

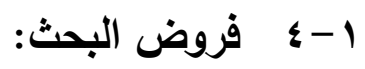

ا. . هناك فروق ذات دلالة احصائية في استخدام التغذية الراجعة النهائية المباشرة الفورية والمتاخرة في مستوى تعلم

حركات السباحة الحرة.

r. هنالك فروق ذات دلالة أحصائية في نتائج الاختبار بين مجموعتي البحث التجريبينين (التي استخدت التغذية

الراجعة النهائية المباشرة الفورية والمتاخرة ) في مستوى تعلم حركات السباحة الحرة.

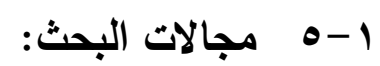

1 - 1 - المجال البشري: عينة من طلاب المرحلة الثانية اكلية التربية البدنية وعلوم الرياضة اجامعة بغداد.

1 - - المجال المكاني: المسبح المغلق كلية التربية البدنية وعلوم الرياضة الجادرية



r- المبحث الثاني: الدراسات النظرية.

r - ب التغذية الراجعة:

ان التغذية الراجعة هي معلومات لتصحيح الاداء تصل الى الدماغ ويتم تزويد المتعلم معلومات دقيقه عن

طبيعة المهارة التي تعلمها كما انها نسهم في تثبيت المعلومات وترسيخها ومن ثم نساعد على رفع مسنوى الاداء في المهمات التعليميه (r:09:)، وعرفت التغذية الراجعة بانها المعلومات بين الهدف المحدد للاداء والاداء المنفذ.(

r-1 - ا اهمية التغذية الراجعة:

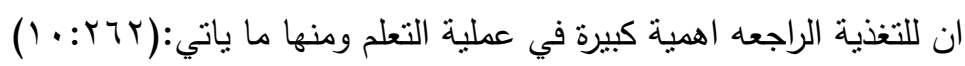

1. تعمل على اعطاء نتيجة للمتعلم اذا كانت صحيحة او خاطئة.

r. تشجع المتعلم على الاستمرار في عملية التعلم خصوصا عند الاداء الصحيح.

r. وصول المتعلم الى قناعه عن نتيجته من خلال معرفة اخطائه 
ء. ان التغذية الراجعه تتشط المتعلم وتزيد مستوى الدافعية لديه.

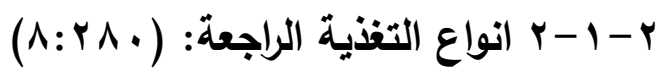

$$
\begin{aligned}
& \text { 1. تغذية راجعة حسب المصدر (داخلية وخارجية ) } \\
& \text { r. تغذية راجعة حسب زمن تقديمها (فورية ومؤجلة ) } \\
& \text { r. تغذية راجعة حسب شكل معلوماتها (لفظية و مكتوبة) } \\
& \text { ء. تغذية راجعة حسب التزامن مع الاستجابة ( متلازمة ونهائية ) } \\
& \text { 0. تغذية راجعة الايجابية والسلبية } \\
& \text { 7. تغذية راجعة المعتمدة على المحاولات المتعددة. }
\end{aligned}
$$

ان التغذية الراجعه الفورية تتصل وتعقب السلوك مباشرة وتزود المتعلم بالمعلومات او التوجيهات والارشادات

اللازمة لتعزيز السلوك وتطويره، اما التغذية الراجعه المؤجلة هي التي تعطي للمتعلم بعد مرور مدة زمنية على انجاز المهمه او الاداء وقد تطول او تقصر . وقد عرفها (مصطفى السايح (.... هي المعلومات التي تعطى للطلاب اثناء الاداء. (van Dyke) (1) هي المعلومات التي عليها الطلاب بشكل فوري اثثاء الاداء. اما التغذية الراجعة المؤجلة او المتاخرة هي المعلومات التي يحصل عليها الطلاب من المدرس بعد الانتهاء من الاداء بمدة لغرض استثمار المعلومات الحسية الداخلية.

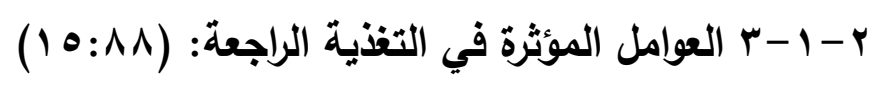

ا. ـ مرحلة التعلم: يجب ان تراعى مرحلة التعلم في اعطاء التغذية الراجعة من حيث كم ونوع المعلومات المقدمة

للمتعلم.

r. . وضوح المعلومات المقدمة للمتعلم ودقتها حيث يجب ان تكون المعلومات واضحة ومناسبة لمستوى المتعلم

$$
\text { ولخبراته. }
$$

r. . وقت اعطاء التغذية الراجعة: حيث يجب ان يكون المدرب قادر على اختيار الوقت المناسب والذي يحدده نوع

$$
\text { النشاط ونوع المهارة. }
$$

ع. ـ كمية المعلومات المقدمة للمتعلم حيث يجب ان تتتاسب كمية المعلومات مع مرحلة التعلم وتزداد كمية

$$
\text { المعلومات المقدمة كتغذية راجعة في مرحل التعلم الاولى. }
$$

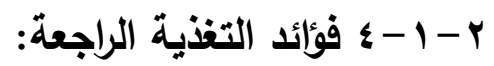

ان التغذية الراجعة لها فوائد كثيرة حيث انها تثبت شكل الحركة بالوضع الصحيح في مرحلة مبكرة من التعلم وفسح مجال للمتعلم باكتثاف اخطائه بنفسه وتجنب اعطاء التغذية الراجعة بعد كل محاولة بالنسبة للمنقدمين واعطائها بعد كل محاولة للمبتدئين والتدرج في سحبها واعطاء التغذية الراجعة بنسبة من التكرارات بحسب منطلبات الاداء لنتبيت 
مجلة كلية التربية الرياضية ـ جامعة بغداد ** المجلا الثلاثون ** العدد الثاني * لسنة r. I1

الدافعية والتعزيز واستخدام مبادى التعزيز الايجابي، واستخدام مبادىه التعزيز السلبي لتأثير حول الاختبارات الغير صحيحة وتجنبها وهذه بدورها تزيد من نطور التعلم الصحيح.(Y):YVY)

$$
\begin{aligned}
& \text { r-r مراحل تعلم السباحة: ( P:०): } \\
& \text { 1. تمارين التكيف على المحيط الجديد } \\
& \text { r. تمارين الغطس والتتفس } \\
& \text { r. - تمارين الطفو: } \\
& \text { ع. تمارين الانزلاق الأمامي (الانسياب): } \\
& \text { 0. تمارين الانزلاق مع حركة الرجلين: } \\
& \text { 7. تمارين الانزلاق مع حركة الرجلين والتتفس: } \\
& \text { V. تمارين الانزلاق مع حركة الذراعين: } \\
& \text { ^. تمارين الانزلاق مع حركة الذراعين والتنفس: } \\
& \text { 9. تمارين الانزلاق مع حركة الرجلين والذراعين والتتفس: } \\
& \text { • }
\end{aligned}
$$

r-r وصف الأداء الحركي للسباحة الحرة The Front crawl stroke:

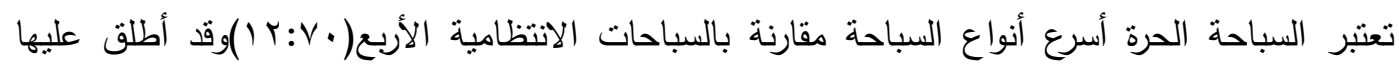

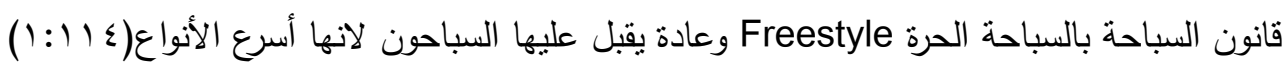

ويثير القانون الدولي في السباحة المادة (0 - () إمكان السباح استخدام أي طريقة في السباحة ما عدا

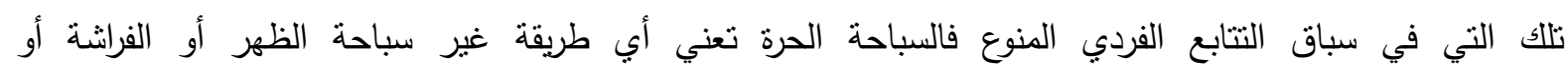

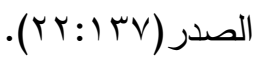

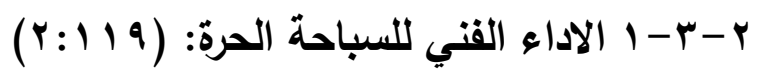

• الشد بالذراع تحت الماء:

ل الثد على شكل حرف (S).

لثي المرفق لأعلى (•9) درجة حسب مسافة السباق.

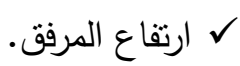

ل امتداد الذراع لأقصى مسافة في كل دورة ذراع.

• التزايد التدريجي لسرعة الذراع. 
مجلة كلية التربية الرياضية - جامعة بغداد ** المجلد الثلاثون * العدد الثاني ** لسنة

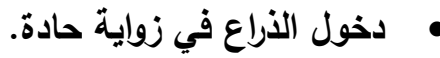

• الحركة الرجوعية للاذراعين:

ل إكون المرفق مرتفعاً.

ك الاسترخاء الكامل للذراع.

ك دخول الذراع أمام الكتق.

• ضريات الرجلين:

$\checkmark$

$\checkmark$ انثاء خفيف للركبتين أثناء ضربات الرجلين لأسفل.

ل امتداد الركبتين عند أداء ضربات الرجلين لأعلى.

$\checkmark$

ل أداء ضربات الرجلين في مدى صغير •

وضع الجسم والتنفس:

ل الوضع الأفقي المستقيم للجسم.

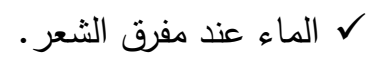

ح حركة تبادلية للذراعين (وتكون الذراع في وضع عكس الأخرى).

ل تدوير الرأس لأخذ الثهيق وليس رفعها.

$\checkmark$

ل التركيز على إخراج الزفير كاملاً.

\section{ب- المبحث الثالث: منهجية البحث واجراء|ته الميدانية.}

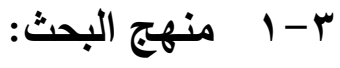

اعتمدت الدراسة المنهج التجريبي بطريقة التصميم ذو المجموعتين المتكافئتين (مجموعتين تجريبية واخرى

ضابطة) لملائمة طبيعة مشكلة البحث.

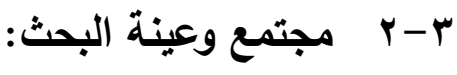

تم تحديد مجتمع البحث بطلبة المرحلة الثانية في كلية التربية البدنية وعلوم الرياضة من غير المتعلمين

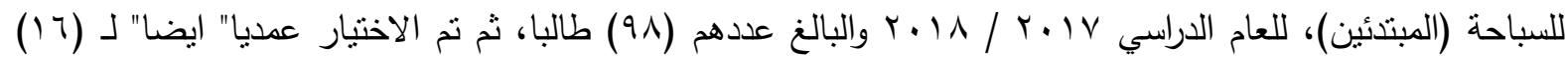
طالبا كعينة للبحث، حيث مثلت نسبة العينة (r.7 (\%) من مجتمع البحث وهذا ما يدل على ان العينة مثلت المجتمع تمنيلا صادقا وبنسبة عالية، اذ نم اختبارهم من مجتمع البحث من غير المتعلمين للسباحة ومن نفس المرحلة العمرية 
مجلة كلية التربية الرياضية - جامعة بغداد ** المجلا الثلاثون * العدد الثاني * لسنة r. IN

وباطوال واوزان منقاربة لغرض التاكيد من عدم وجود متغيرات دخيلة قد توثر على نتائج البحث، وبعد ان نم اختيار العينة والتاكد من تجانسهم تم توزيع عشوائيا الى مجموعتين:

ا. . المجموعة التجريبية الاولى: (^) طلاب يتم تعليمهم باستخدام طريقة التغذية الراجعة النهائية المباشرة (الفورية). r. المجموعة التجريبية الثانية: (^) طلاب يتم تعليمه باستخدام التخذية الراجعة المتاخرة (بعد عدة تكرارات).

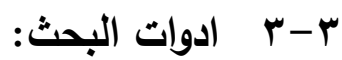
استخدمت الادوات التالية في البحث:

$$
\begin{aligned}
& \text { المصادر والمراجع العلمية } \\
& \text { شريط قياس } \\
& \text { المقابلات الثخصية } \\
& \text { • • } \\
& \text { المسبح المغلق للكلية } \\
& \text { • حاسبة شخصية } \\
& \text { فريق العمل المساعد* } \\
& \text { حاسبة لابتوب } \\
& \text { التجربة الاستطلاعية } \\
& \text { اختبار السباحة الحرة. }
\end{aligned}
$$

ب- 2 التجرية الاستطلاعية:

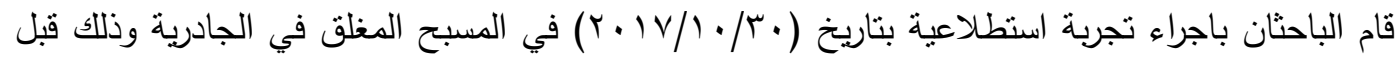
البدء بتطبيق المنهج التعليمي للسباحة لطلبة المرحلة الثنانية لغرض التاكد من كفاء فريق العمل المساعد في كيفية اعطاء التغذية الراجعة وفق الطريقة المحددة لكل مجموعة وكذاللك التاكد من كفاية الوقت المخصص للوحدات التعليمية والاختبارات الخاصة بالبحث.

r- ب طرية اعطاء التغذية الراجعة: 
في ما يلي الطريقة المستخدمة لاعطاء التغذية الراجعة لكل مجموعة من المجموعتين التجريبيتين وكما يلي:

\section{1. المجموعة التجريبية الاولى (النهائية الفورية المباشرة ):}

استخدمت هذة المجموعة طريقة التغذية الراجعة النهائية الفورية (المباشرة) في تعليمهم حركات السباحة

الحرة، حيث كانت المعلومات التصحيحية والتعزيزية تعطى للمتعلم بعد كل نكرار مباشرة علما ان مجموع التكرارات لكل حركة كانت منساوية لدى المجموعتين التجريبيتين وان الاختلاف في وقت اعطاء التغذية الراجعة فقط. r. المجموعة التجريبية الثانية (المتاخرة):

استخدم افراد هذه المجموعة طريقة التخذية الراجعة المتاخرة في تعليمهم لحركات السباحة الحرة، حيث كانت المعلومات التصحيحية والتعزيزية تعطى لهم بعد كل (T) تكرارات لكل تمرين او حركة من حركات السباحة الحرة.

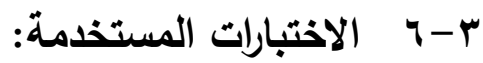 وتضمن الاختبارين مايلي: \\ ا ـ اختبارتقييم الاداء الحركي للسباحة الحرة:}

تضمن الاختبار الاول السباحة الحرة لمسافة (15) منز واعطاء التقييم بالدرجات لدقة الاداء الحركي من قبل لجنة مؤلفة من ثلاثة مدرسين للمادة* * حيث كان اعطاء الدرجة من (15) موزعة كما في الجدول رقم (1) حيث نم اعطاء درجات التقييم وفق ما هو متبع ضمن الثقييم الفصلي للجانب العملي من المادة، وتضمن الاختبارالتفاصيل التالية: - 20 - n

$$
\begin{aligned}
& \text { اسم الاختبار : اختبار الاداء الحركي للسباحة الحرة } \\
& \text { الهدف: تقييم الاداء الفني للسباحة الحرة. }
\end{aligned}
$$

طريقة الاداء: وقوف المختبر داخل الحوض قرب الحافة بحيث يكون ظهره مواجها لها، ثثي احدى الرجلين الى الخلف ووضع قدمها على الحافة، رفع الذراعين الى الاعلى، عند سماع الايعاز بالبدأ، ثني الجذع اماما" بمستوى سطح الماء ودفع الحافة، اداء الانسياب وحركات الذراعين والرجلين والتتفس لمسافة (15) م. طريقة التسجيل: اعطاء درجات التقييم من قبل اللجنة لكل جزء من اجزاء الاداء الحركي وكما موضح في

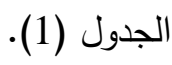

$$
\begin{aligned}
& \text { * مدرسي المادة: } \\
& \text { - أ.م.د. بسار صبيح مدرس سباحة كلية التربية الرياضية / ج بغداد الماده }
\end{aligned}
$$

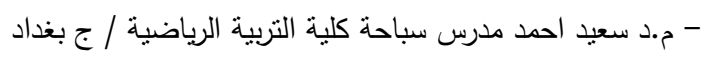

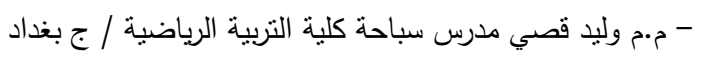


مجلة كلية التربية الرياضية - جامعة بغداد ** المجلد الثلاثون ** العدد الثاني * لسنة

$r .11$

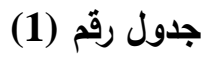

درجات التقييم لأختبار الاداء الحركي للسباحة الحرة

\begin{tabular}{|c|c|c|}
\hline القيمة|لعليا للارجة (15) & أعلى قيمة & جزء الحركة \\
\hline & $\begin{array}{l}2.5 \\
2.5 \\
2.5 \\
2.5 \\
\text { درجة درجة } 5 \text { درجة } 2.5\end{array}$ & حركة التتفس الجسم $ح ر$ حركة الرجلين \\
\hline
\end{tabular}

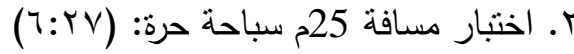

تضمن الاختبار الثاني السباحة الحرة لقطع مسافة 25م والمعتمد في رسالة ماجستيرتم فيها استخدام

الاختبار مع عينة من نفس الاعمار والمرحلة الدراسية، واشتملت تفاصيل الاختبار على مايلي:

اسم الاختبار : اختبار 0rم سباحة حرة

• الهدف: قياس مسافة السباحة المقطوعة من قبل المختبر بوحدة ( المنر واجزائه )

طريقة الاداء: يقف المختبر داخل الحوض عند الحافة بحيث يكون ظهره مواجه للجدار ووجهه مواجهة للماء، يثني احدى الرجلين من الركبة الى الخلف ويستتد بقدمها على الجدار، يرفع الذراعين عاليا" امام الكتقين وبشكل متوازي، عند اعطاء اثارة البدأ يثني المختبر الجذع اماما" ليكون بشكل افقي مع سطح الماء، بعدها يدفع الجدار بالرجل المثثية ويؤي الانسياب الامامي وبعدها يستمر بالسباحة محاولا" الوصول الى الحافة الاخرى (اي

$$
\text { يحاول المختبر السباحة وقطع المسبح عرضيا" من جانب الى اخر ) }
$$

طريقة النتجيل: تقاس مسافة السباحة التي يقطعها المختبر من بداية حركته وحتى النقطة الني يصل اليها.



تم استخدام اختبارين في تحديد وقياس مستوى التعلم الذي حققه كل فراد من افراد عينة البحث بدقة بعد تطبيق المنهج التعليمي للسباحة حيث تم اجراء الاختبارين في المسبح المغلق لكلية التربية البدنية وعلوم الرياضة في 
مجلة كلية التربية الرياضية ـ جامعة بغداد ** المجلد الثلاثون ** العدد الثاني ** لسنة $r$. I 1

تم استخدام البرنامج الاحصائي (spss) للتوصل الى النتائج حيث تم اعتماد القوانين التالية:

$$
\begin{aligned}
& \text { • النسبة المئوية \% } \\
& \text { • الوسط الحسابي. } \\
& \text { • الانحراف المعياري ع. } \\
& \text { • اختبار T للعينات المتتاظرة } \\
& \text { • اختبار T للعينات المستقلة. }
\end{aligned}
$$

ع - المبحث الرابع: عرض ومناقشة النتائج.

ع - 1 عرض نتائج الاختبارات القبلية والبعدية لمجموعتي البحث التجريبية:

\begin{tabular}{|c|c|c|c|c|c|c|c|}
\hline \multirow{2}{*}{ الالالة } & \multirow{2}{*}{ مؤشر الدلالة } & \multirow{2}{*}{ المحسوبة } & \multicolumn{2}{|c|}{ الاختبار البعدي } & \multicolumn{2}{|c|}{ الاختبار القبلي } & \\
\hline & & & ف هـ & ف & سَ بعدي & سَ قبلي & \\
\hline معنوي & $\cdots$ & $\Lambda . V Y$ &.$V V$ & 1.V0 & 9 & r. ro & الاداءالحركي (درجة) \\
\hline معنوي & $\ldots$ & $V . . r$ & $1 . \mathrm{rA}$ & 9 & Ir.AV & $r . \wedge V$ & مسافة السباحة (م ) \\
\hline
\end{tabular}

ع - - - عرض نتائج الاختبارات القبلية والبعدية في متغيرات البحث لاى مجموعة البحث التجريبية الأولىى:

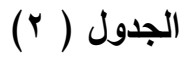

النتائج الاحصائية للمقارنة بين الاختبارين القبلي - البعدي للمجموعة التجريبية الاولى المي 
مجلة كلية التربية الرياضية - جامعة بغداد ** المجلد الثلاثون ** العدد الثاني ** لسنة

$r, 1 \Lambda$

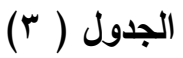

النتائج الاحصائية للمقارنة بين الاختبارين القبلي - البعدي للمجموعة التجريبية الثانية

\begin{tabular}{|c|c|c|c|c|c|c|c|}
\hline \multirow{2}{*}{ الالالة } & \multirow{2}{*}{ مؤشر الدلالة } & \multirow{2}{*}{$\begin{array}{c}\text { T } \\
\text { المحسوية }\end{array}$} & \multicolumn{2}{|c|}{ الاختبار البعدي } & \multicolumn{2}{|c|}{ الاختبار القبلي } & \\
\hline & & & ف هـ & ف & سَ بعدي & سَ قبلي & تغير ووحدة \\
\hline معنوي & $\ldots$ & $9 . \leqslant 7$ &..$\leqslant r$ & $\varepsilon \ldots$ & 7.74 & r.Tr & الاداءالحركي (درجة) \\
\hline معنوي & $\cdots \cdots$ & $7 . .7$ & $1 . . r$ & T. YO & $9 . \wedge \vee$ & r.tr & مسافة السباحة (م ) \\
\hline
\end{tabular}

يبين الجدولين (r) و (r) النتائج الاحصائية للمقارنة بين الاختبارات القبلية والبعدية لمجموعتي البحث حيث يظهر وجود فروق معنوية بين الاختبارين القبلي والبعدي في تقييم الاداء الحركي ومقدار مسافة السباحة المقطوعة ولكلا المجموعتين ويعزو الباحث هذا النطور لأفراد المجموعتن التجريبية الى حدوث حالة المنحنى الإيجابي من منحنيات التعلم إذ يكون هناك تحسن بطيء في البداية ثم يعقبه تحسن سريع ويحدث هذا المنحنى عندما تكون الحركة

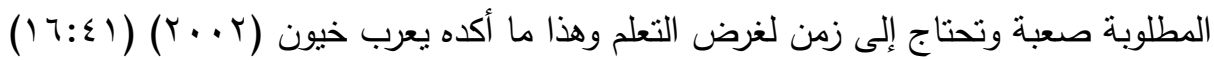

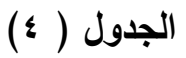

النتائج الاحصائية للمقارنة بين مجموعتي البحث التجريبية الاولى والثثانية في الاختبارات البعدية

\begin{tabular}{|c|c|c|c|c|c|c|c|}
\hline \multirow{2}{*}{ الدلالة } & \multirow{2}{*}{$\begin{array}{c}\text { مؤثر الدلالة } \\
\text { Sig }\end{array}$} & \multirow{2}{*}{ المحسوية } & \multicolumn{2}{|c|}{ مج التجريبية الثانية } & \multicolumn{2}{|c|}{ مج التجريبية الاولى } & \multirow{2}{*}{ المتغير } \\
\hline & & & $\varepsilon$ & سَن & $\varepsilon$ & سَن & \\
\hline معنوي & $\cdots \varepsilon$ & 1.97 & $r . . T$ & 7.74 & r.Vr & 9 & الاداء الحركي (درجة) \\
\hline معنوي & $\ldots r$ & T.EV & S.To & 9.^v & r.Vr & IE.rV & مسافة السباحة (م) \\
\hline
\end{tabular}

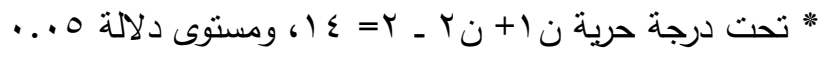

اما الجدول (ع) يبين النتائج الاحصائية للمقارنة بين مجموعتي البحث في نتائج الاختبارات البعدية ولكلا المتغيرين الاداء الحركي ومقدار مسافة السباحة حيث يظهر الفرق معنوي ولصالح المجموعة التجريبية الاولى (مجموعة التغذية الراجعة المباشرة الفورية) حيث يعزو الباحث ذلك التفوق الى الوحدات التعليمية كانت كافية لتعلم المهارة وهذا ما يتقق مع ذكره (محمد علي القط 999 (1) حيث ذكر بان المناهج التعليميه يقاس نجاحها بمدى التقدم الذي يحققه الطالب في نوع النشاط المحدد.(0:9) وكذلك استخدام نوقيتات مختلفة للتغذية الراجعه له الاثر الواضح في تعلم المهارة وان طريقة التدخل في الوقت المناسب لاعطاء المعلومات التي اسهمت في نطوير مستوى الاداء وتحسين نوافق العمليات الحسية الناتجة عن الاثارة لهذه المعلومات مع مستوى الاداء الحركي.(01:乏) وهذا يتفق ما وصلت اليه ( Christina) 1996) اذ اثتت انه في مراحل اكتساب المهارة الاولية يجب اعطاء تغذية راجعة بعد كل محاولة بمعنى الاستمرار في 
ان التكرار في الاداء يعطي نتائج ايجابية وهذا ما اتفق معه (عصام محمد 9 I I ) حيث بين انه كلما زاد

التكرار للمهارة اصبحت اكثر اتوماتيكية ويتتناقص التوتر وتصبح الحركة اكثر اتقانا.(و (0)

وكذلك يعزو الباحثان النتائج الى نجاح استخدام التكرارات مع التغذية الراجعه المناسبة التي تعد وسيلة فعالة في تتفيذ الاساليب التعليمية وهذا يتفق ما اكده (Mosten 1981) حيث بين ان القاعدة الاساسية والضرورية في تعلم



وكذلك ان استخدام التغذية الراجعة الفورية يساعد المتعلم على اتقان الحركات الثانوية او الفرعية التي تمثل في مجموعها المهارة المطلوب تعلمها وتحقق التتاسق بين هذه الحركات مما يجعل ادائها في تتابع صحيح وزمن مناسب

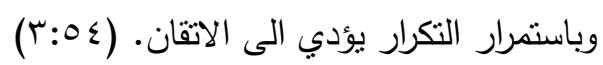

وان الباحثان توصلا الى ان التغذية الراجعة الفورية لها اثر في زيادة ادراك المتعلم بالمقارنه مع التغذية الراجعة المؤجلة لان المتعلمين في التغذية الراجعه الفورية سيقيمون اداءهم مباثرة ويقارنون بين تتفيذ المهارة والاداء الصحيح وبالتالي تحديد الخطأ والصحيح في الاداء.

\section{ه- المبحث الخامس: الاستنتاجات والتوصيات. 0-1 الاستتتاجات:}

ا. للتغذية الراجعة الفورية (المباشرة) والمتأخرة تأثثرا ايجابيا في تعلم حركات السباحة الحرة. r. فاعلية التغذية الراجعة الفورية في المجموعة الاولى لعينة البحث افضل من المجموعة الثانية في الاختبارات البعدية. r. فاعلية التغذية الراجعة الفورية (المباشرة) افضل من التغذية الراجعة المتأخرة في تعلم حركات السباحة الحرة للمبتدئين

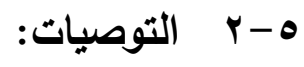

1. الاهتمام باستخدام معلومات التغذية الراجعة بمختلف انواعها في تعليم حركات السباحة الحرة للطلاب المبتدئين r. التركيز على استخدام معلومات التغذية الراجعة الفورية (المباشرة ) في تعليم حركات السباحة الحرة للطلاب

المبندئين r. ضرورة أجراء بحوث مشابهة في هذا المجال لعدم وجود بحوث مشابه لأنواع السباحة الاخرى في تعليم أنواع السباحة.. 
• أسامة كامل راتب؛ تعلم السباحة. طץ: (القاهرة، دار الفكر العربي، ع^9 ()).

• أسامة كامل راتب وعلي محمد زكي؛ الأسس العلمية للسباحة. طا : (القاهرة، دار الفكر العربي، 991 (1).

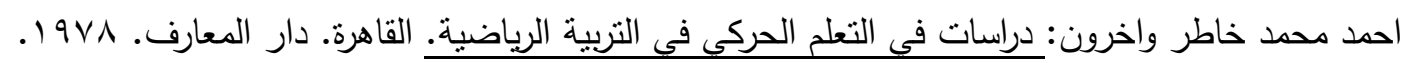

• بسطويسي احمد بسطويسي: أسس ونظريات الحركة القاهرة، دار الفكر العربي. 997 1.

عصام محمد امين: بايولوجية تدريب السباحة القاهرة، دار الكتب، I9VV I .

• سامر سعد الله. اثر منهج نعليمي مقترح في تعلم السباحة الحرة (الزحف ). رسالة ماجستير، كلية التربية الرياضية،



فيصل العياش واخرون؛ رياضة السباحة. بغداد. دار الفكر العربي. 1919.

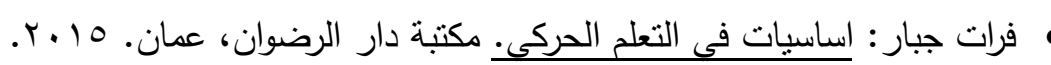

• محد علي القط: وظائف اعضاء التدريب الرياضي مدخل تطبيقي، طا، القاهرة. دار الفكر العربي. 1999 .

• محد محمود الحيلة: التصميم التعليمى نظرية وممارسة، عمان. دار الميسرة للطباعه والنشر ، 999 . .

• مصطفى السايح: اتجاهات حديثة في تدريس التربية البدنية الرياضية القاهرة. مديرية مطبعة الجامعة. 1990.

• مفيد الناجي؛ السباحة طرق وفوائد. طا، جا: (بيروت، منشورات المكتبة العصرية، ؛99 1) )

• مفتي ابراهيم حماد:التدريب الرياضي (التخطيط والتدريب). القاهرة. دار الفكر العبي 19911.

• وجيه محجوب. التعلم وجدولة التدريب. بغداد: مكتب العادل للطباعة، . ... . .

• وسام صلاح وسامر يوسف: التعلم الحركى بين النظرية والتطبيق ، بيروت. دار الكتب العلمية، ـ ا. r.

• يعرب خيون: التعلم الحركى بين المبدأ والتطبيق: (بغداد، مكتب الصخرة للطباعة، r . . r).

- Brinko K (1993.) The practice of giving feedback to improve teaching: what is effective The journal of Higher Education. 64 no,1993 .

- Christina R.w.Human performance determinants in sport ;Korean society of sport ,Korea. 1996.

- Mosten Muska, Teaching physical Education, carless. Merrill publishing company, Ohio, 1981 ,

- Fina-Hand Book, (1998 - 2000),

- Magill ,A ,Richard, Motor Learning and Control, Boston. Mcg row hill. 2004. 